\title{
VALORES MORAIS DOS ESTUDANTES QUE PARTICIPARAM DOS PROTESTOS NO BRASIL EM 2013 E 2015
}

Marco Aurélio de Campos JUNIOR ${ }^{1}$

Daniel CALBINO2

Ludmila de Vasconcelos Machado GUIMARÃES 3

\author{
${ }^{1}$ Graduando em Engenharia de Alimentos, UFSJ. marco.junior@ufv.br \\ 2 Doutor em Administração pela UFMG. Docente da UFSJ. dcalbino@ufsj.edu.br \\ ${ }^{3}$ Doutora em Administração pela UFMG. Docente do CEFET-BH. ludmilavmg@gmail.com
}

Recebido em: 12/05/2016 - Aprovado em: 25/11/2016 - Disponibilizado em: 18/12/2016

\begin{abstract}
RESUMO:
Os últimos anos no Brasil têm sido marcados por um grande número de manifestações que têm ocorrido nas ruas e em redes sociais, registrando também fortes discursos de moralidade que regem os debates políticos no país.Neste contexto, o presente artigo busca compreender os valores morais de um grupo de estudantes universitários que participaram dos movimentos de rua nestes anos. Para tal, foi realizada uma pesquisa quantitativa com a utilização de dilemas morais aos quais os estudantes, se posicionavam referente às tomadas de decisões éticas nas esferas macro e micro sociais. Os resultados da pesquisa apontaram que os discentes sustentam uma defesa de valores moralistas nas supostas decisões de um futuro profissional ético, porém contradições marcadas por decisões antiéticas referentes a microesfera que estão inseridos. Registrou ainda uma crença de que nunca se roubou tanto no Brasil e que a população brasileira é corrupta, porém uma visão a-crítica de suas próprias condutas, o que aponta para a necessidade de reflexões teóricas sobre o contexto atual de moralismo no país.
\end{abstract}

Palavras-chave: Corrupção, Moralismo, Moralidade, Manifestações, estudantes.

\begin{abstract}
:
Through the large number of events that have occurred in the country and moralists waves governing political debates in Brazil, this article seeks to understand the moral values of students of Federal University of morality and moralism present in society. To this end, it carried out a quantitative research with moral dilemmas to which the students positioned themselves regarding the decisions in the spheres macro and micro social. The survey results pointed to a defense of moral values in the alleged moral decisions of a professional future, but there were contradictions marked by unethical decisions for the daily lives of students. Like, he registered a belief that never stole both in Brazil and the Brazilian population is corrupt, but a vision - critical of their own ethical and moral conduct.
\end{abstract}

Keywords: Corruption, Moralism, Morality, Manifestations.

\section{Introdução}

O fenômeno das manifestações sociais que eclodiram em diversas cidades do país entre os anos de 2013 e 2016 tiveram como pauta, melhorias na educação, transporte público, saúde, no modo de se fazer política, entre outras. Porém, a discussão da literatura sobre tais manifestações ainda está condensada em poucos autores como, Singer (2013), Botelho (2013), Durigan e Renó (2015), Loyola (2015), o que indica uma escassez analítica neste cenário acadêmico.

Para Loyola (2015) e Silva e Santos (2009) essa é uma importante discussão inclusive no processo de alienação ou desalienação dos canais de informação que, 
devido a sua importância no cotidiano dos brasileiros tentam defender o que é certo ou errado em relação as ações tomadas e praticadas no país.

Segundo Vieira Pinto (2013) as manifestações de rua pelo país, mesmo quando não alcançaram os seus objetivos iniciais, acabaram sendo benéficas para a sociedade, a medida em que a população passa a desenvolver de certa forma maior participação política.

Se em 2013 os movimentos sociais que foram as ruas reivindicavam questões vinculadas a estrutura, qualidade de gestão e eficiência pública, em 2015 e 2016 as bandeiras migraram para um discurso que envolve uma polarização partidária, muito em função do impeachment ${ }^{1}$ presidencial (PERES et al., 2015; LOYOLA, 2015).

Da mesma forma, se por um lado esses movimentos avançam na construção e conscientização da cidadania, por outro, principalmente pelos discursos ideológicos de moralismo e moralidade, merecem análises.

\footnotetext{
${ }^{1}$ Trata-se de um termo que define o processo de cassação de mandato do chefe do Poder Executivo pelo Congresso Nacional, pelas Assembleias Estaduais ou pelas Câmaras Municipais na ocorrência de crime de responsabilidade, abuso de poder, desrespeito às normas constitucionais ou violação das cláusulas pétreas previstos na $\mathrm{CF} / 88$. Contudo, para que isso aconteça é necessário que se tenha provas concretas, e se enquadre nas hipóteses previstas no art. 85 da $\mathrm{CF} / 88$, ou seja, que tenha cometido um crime de responsabilidade, que inclui, entre outros, crimes contra a existência da União, o exercício de direitos políticos, sociais e individuais e contra a probidade administrativa (PERES et al., 2015).
}

É no bojo dessa discussão que se propõe como objetivo central do artigo compreender os valores morais de estudantes universitários que saíram às ruas para protestar. Enquanto escopo analítico propõese por meio de uma pesquisa de natureza quantitativa, mapear como os estudantes ${ }^{2}$ da Universidade Federal de São João Del-Rei Campus Sete Lagoas, se situam sobre os pontos de vistas de moralismo e moralidade na sociedade por meio de alguns dilemas morais $^{3}$. Justifica-se este recorte pelo fato de o grupo formado por estudantes universitários representarem de um geral a classe média brasileira,que foi protagonista pelas manifestações de 2013, 2015 e 2016.

Em termos estruturais, o trabalho encontra-se dividido em um referencial teórico com duas etapas, na primeira realizará uma construção histórica dos movimentos de rua mostrando as suas semelhanças $\mathrm{e}$ diferenças. Na segunda etapa abordará uma discussão sobre as distinções entre a moralidade e o moralismo e como a distinção permeia nos movimentos de rua. Em seguida serão apresentados os percursos metodológicos da pesquisa quantitativa, assim

\footnotetext{
${ }^{2}$ Vale ressaltar que todos os estudantes que responderam a essa pesquisa participaram ativamente, saindo às ruas, das manifestações ocorridas entre 2013 e 2016.

${ }^{3}$ Entende-se por dilemas as tomadas de decisões que envolvem situações ao qual se deve escolher alternativas que podem ser contraditórias e/ou igualmente insatisfatórias ao sujeito e a sociedade.
} 
como os seus critérios de seleção. Na quarta etapa do trabalho serão apresentados os resultados e discussões obtidos e por fim serão apresentadas as considerações finais do trabalho.

\section{Breve contextualização manifestações de 2013, 2015 e 2016}

As manifestações de 2013 surgem como um movimento social iniciado pelo Movimento Passe Livre, que aos poucos se transformou em uma grande manifestação popular. Esta mudança traz consigo um brado de ordem e um desabafo contra a corrupção e o modo de se fazer política no país (BORGES et al; MEDEIROS, 2014; BOTELHO; 2013; SINGER, 2013).

\section{Medeiros (2014) retrata alguns}

protestos, como em agosto de 2003 onde estudantes da Bahia causaram a "Revolta do Buzu", ou em Florianópolis em 2004 e 2005 com a "Revolta da Catraca" como sendo movimentos iniciados por estudantes. Os protestos se assemelham muito com as manifestações de junho de 2013, quando o reajuste no valor das passagens se deu no meio do ano e o aumento proposto também era de 0,20 centavos.

$\mathrm{O}$ autor ainda explica que tal efeito ocorre devido aos discentes estarem no meio de suas atividades acadêmicas e não de férias como ocorre em janeiro, - época em que os reajustes normalmente são feitos - o que contribuiu para maior organização e até mesmo no comparecimento aos protestos por parte dos estudantes, o que desencadeia em uma onda de protestos com várias bandeiras pelo país.

No entanto o mesmo não ocorre com as manifestações no ano de 2015 e 2016, quando eram caracterizadas por uma contestação ao modo de se fazer política, ao aumento do preço da gasolina, as denúncias de corrupção envolvendo a Petrobrás e pedidos de impeachment da presidenta Dilma.

Borges et al (2014) e Loyola (2015) complementa que os movimentos de 2015 não são uma contestação aos partidos,mas as concepções de esquerda e direita de governo e as suas oposições causadas pela tensão política das eleições de 2014.

A eleição daquele ano foi um momento de extrema tensão política vivenciada no país, ao qual estabeleceu-se uma polarização entre os eleitores de Dilma e Aécio Neves. Após a pequena margem de vitória da presidenta, a situação resultou em um intenso descontentamento por parte de uma parcela de brasileiros que eram contra a sua reeleição (PERES et al., 2015; LOYOLA, 2015).

O jornal Datafolha ${ }^{4}$ fez uma pesquisa que aponta para uma mudança no perfil dos

${ }^{4}$ Dados disponíveis em: <http://datafolha.folha.uol.com.br/opiniaopublica/2015 /03/1604284-47-foram-a-avenida-paulista-em-15-demarco-protestar-contra-a-corrupcao.shtml>. Acesso em 20/02/2016 
manifestantes entre os dois anos. Enquanto em 2013 o perfil dos manifestantes em sua grande maioria era formado por estudantes e por uma classe conhecida como novo proletariado $^{5}$, em 2015 e 2016 esse perfil se inverte, uma vez que $68 \%$ das pessoas presentes nas manifestações recebem cinco salários mínimos ou mais por mês.

$$
\text { Loyola (2015) ressalta outras }
$$
mudanças importantes na organização das manifestações. Se nos eventos de 2013 as pessoas levavam cartazes feitos de cartolina, em 2015 e 2016 eram confeccionados em escala e distribuídos a população, trios elétricos puxavam os manifestantes e coreografias foram ensaiadas. Além disso, os manifestantes saiam as ruas uniformizados com camisas da seleção brasileira, bandeiras do Brasil e ou cores vermelhas em apoio ao governo.

Com o intuito de compreender melhor asmudanças inclusive nas temáticas das manifestações, Loyola (2015) realizou uma análise dos cartazes utilizados nos protestos, ilustrando os câmbios nas narrativas, na tabela a seguir:

\footnotetext{
${ }^{5}$ Analisando as pesquisas disponíveis sobre a composição social dos acontecimentos de junho de 2013, André Singer denomina "novo proletariado: os trabalhadores, em geral jovens, que conseguiram emprego com carteira assinada na década lulista (20032013), mas que padecem com baixa remuneração, alta rotatividade e más condições de trabalho" (SINGER, 2013).
}

Tabela 1 - Frequência de aparição dos temas em 2013 e 2015.

\begin{tabular}{c|c|c|}
\hline Tema & $\mathbf{( 2 0 1 3 )}$ & $\mathbf{( 2 0 1 5 )}$ \\
\hline $\begin{array}{c}\text { Reivindicação de } \\
\text { políticas públicas } \\
\text { específicas }\end{array}$ & $29,82 \%$ & $6,06 \%$ \\
\hline $\begin{array}{c}\text { Apoio ao ato de } \\
\text { manifestar-se }\end{array}$ & $36,84 \%$ & $10,06 \%$ \\
\hline $\begin{array}{c}\text { Insatisfação com o } \\
\text { governo atual }\end{array}$ & $28,07 \%$ & $22,72 \%$ \\
\hline Insatisfação com a & & \\
presidenta Dilma & & \\
& & \\
\hline Impeachment & & $10,60 \%$ \\
\hline Intervenção Militar & $0 \%$ & $13,63 \%$ \\
\hline Indignação com a & $5,70 \%$ & $30,30 \%$ \\
\hline corrupção e impunidade & & $100 \%$ \\
\hline Total & & \\
\hline Fonte: Adaptado de Loyo & & \\
\hline & & \\
\hline
\end{tabular}

Fonte: Adaptado de Loyola, 2015, p.15-16.

Os dados ilustram que enquanto o movimento das manifestações populares realizadas em 2013 parecia trazer demandas voltadas para uma discussão de infraestrutura, melhorias na educação, transporte público, saúde (pautadas em um discurso de moralidade), nas manifestações de 2015 e 2016 já trazem uma evidenciação de uma discussão relacionada a insatisfação com o governo atual, ao pedido de impeachment da presidenta Dilma Rousseff, o apoio a uma intervenção militar, que se aproxima de uma narrativa do moralismo apoiada na ideia de

\footnotetext{
6 Se esses dados apresentavam, no ano de 2015, 16,60\% a favor do impeachment em 2016 esse número é significantemente maior, ainda que o escopo analítico da época não tinha como bandeira o impeachment.
} 
que "nunca se roubou tanto no país".

Para uma melhor compreensão das definições conceituais de moralismo e moralidade e sua relação com os protestos, o tópico a seguir se destinará a referida discussão.

\section{Moralismo e Moralidade}

Eger (2013 p.27) define a moral como sendo "um conjunto de normas, aceitas livres e conscientemente, que regulam o comportamento individual e social”. Segundo o mesmo autor, o exercício dessa moral seria a moralidade, podendo ser dividida em moral em ação, prática e praticada.

A moralidade é o que está de acordo com as leis, porém isso não implica que ela seja neutra, pois existe um conjunto de normas e leis que quando se segue o que é moral se segue o que é legal. Segundo Costa(2014, p.24), a moralidade do sujeito é composta por várias etapas ao longo da vida e que se o ambiente em que o sujeito se desenvolve for adequado ele irá se desprender da moralidade alheia e criar o seu próprio conceito de moralidade.

Por outro lado, o moralismo pressupõe a emergência de valores morais incondicionais e tem um efeito desestabilizador no sistema político. Avritzer e Filgueiras (2011, p.8) abordam que erroneamente a compreensão da corrupção aborda agindo apenas nas camadas políticas partidárias e trata a mesma segundo uma concepção moral. Para Viana (2005, p.1):

“O moralista é $\begin{array}{r}\text { uma } \\ \text { pessoa que }\end{array}$
cegamente
discursivamente) a moral
e exige que todas as
pessoas sigam os mesmos
passos. O moralista é um
conservador, um defensor
das normas sociais
estabelecidas [...] Por ter
posse da moral, ele se
torna um pregador,
parecendo um religioso,
que passa a se considerar
uma espécie de juiz, um
Deus, que tem o direito
de julgar todos a partir do
cânone abstrato composto
pelas normas de sua
moral".

Para Schwartzman (1981) as campanhas de moralização normalmente visam por meio de uma falsa revolução agravar a espoliação das classes sociais. Por meio de um discurso moralista a contradição se baseia em dissertar sobre seguir o que é legal, mas na prática, se realizam transgressões constantes, ainda que na microesfera do poder.

Tendo-se em vista a diferenciação entre os dois termos pode se inferir que as manifestações de 2013 trazem consigo uma moralidade muito forte e um desejo de que os investimentos a serem realizados pelos governantes sejam feitos em prol da melhoria de vida da população. As reivindicações de políticas públicas específicas, como apoio ao investimento às áreas da saúde, educação e segurança e apoio a reformas política, 
tributária e ao ato de se manifestar ilustram isso (LOYOLA, 2015).

Já as manifestações de 2015 e 2016 os temas como infraestrutura não fizeram parte das reclamações. Através dos discursos observa-se um brado moralista forte e que através dele tentou-se impor a sua vontade, posteriormente a derrota nas urnas em 2014.Uma variável que pode legitimar este discurso, atualmente é o papel da grande mídia, que para Silva e Santos (2009, p.2):

\section{"O poder de manipulação da mídia pode atuar como uma espécie de controle social, que contribui para o processo de massificação da sociedade, resultando num contingente de pessoas que caminham sem opinião própria. Subliminarmente, através da televisão, das novelas, jornais e internet, é transmitido um discurso ideológico, criando modelos a serem seguidos e homogeneizando estilos de vida".}

Marcos et al.(2015, p.112) considera que a grande mídia possui diversas facetas, atuando por muitas das vezes através de tendências pré-estabelecidas e da manipulação, assim como possui um papel informativo e educacional. "Constituindo um dos mecanismos produtores de subjetividade, influencia a formação dos modos de agir, ser, pensar e interagir dos indivíduos". O autor ainda usa como exemplo de influência da mídia no Brasil alguns dos eventos mais fatídicos do país e que ocorreram com mais facilidade devido a influência dos grandes veículos de comunicação da época, como a Revolta das Vacinas, o golpe militar de 64 e a eleição de Fernando Collor de Mello para a presidência do país. Em cada caso a mídia atuou de forma a disseminar um discurso de moralismo no país.

No que se refere aos atuais movimentos de rua, um fato emblemático é que se durante os movimentos de 2013 os grandes meios de comunicação só começaram a relatar efetivamente os fatos a partir do momento em que os jornalistas que cobriam os eventos passaram a ser agredidos e o movimento tomou grande repercussão (DURIGAN; RENÓ, 2015). Em 2015 e mais recentemente em 2016 as manifestações populares a favor do impeachment foram transmitidas pela maioria dos canais de rede aberta do país, porém houve uma notória mudança quando as manifestações foram de apoio a presidente, tendo um coro midiático baixo e poucos minutos de exposição. No mesmo sentido, a própria cobertura da grande mídia tem enfatizado de que nunca se roubou tanto no país nestes últimos anos (DURIGAN; RENÓ, 2015).

\section{Metodologia}

Em termos metodológicos, com o intuito de compreender os valores morais dos estudantes que participaram dos protestos de rua, realizou-se uma pesquisa quantitativa não probabilística, na qual foram aplicados 135 
questionários estruturados com os estudantes dos quatro cursos vigentes na Universidade Federal de São João Del-Rei - Campus Sete Lagoas. Os questionários foram aplicados no período de 11 a 21 de agosto de 2015 .

A justificativa para a escolha deste recorte empírico ocorreu primeiramente pelo fácil acesso às informações, devido ao fato dos pesquisadores estarem inseridos na presente instituição. Porém, a relevância da opinião deste grupo de estudantes universitários se justifica por representarem de um modo geral, uma classe média que tem reproduzido ativamente as discussões dos valores morais na sociedade brasileira (SINGER, 2013).

A pesquisa se baseou em dilemas morais, compostos por um questionário dividido entre questões de análise macroestrutural e micro estrutural. As análises caracterizadas como macroestrutural abordavam uma realidade ainda distante da discussão do estudante sobre um futuro profissional, bem como, temas aos quais as grandes mídias têm enfatizado (grandes licitações, financiamentos públicos e privados de campanhas). Já a discussão micro estrutural envolveu questões referentes a realidade do próprio cotidiano que o estudante está inserido, ou seja, rotinas de trabalho, na fila do restaurante, na prova da universidade, no troco do caixa, a qual envolve também constantes dilemas morais.
No que se refere a técnica de coleta de dados, foi utilizado com o auxílio do software estatístico SPSS (Statistical Package for the Social Sciences), licenciado, que possibilitou por meio de ferramentas estatísticas descritivas, transformar os dados quantitativos em informações relevantes à cerca da compreensão do tema analisado.

\section{Resultados e Discussão}

A pesquisa realizada alcançou um total de 135 alunos do Campus, destes 50,4\% das pessoas entrevistadas eram mulheres (68) e $49,6 \%$ homens (67), o que corresponde a um total de $15,83 \%$ dos estudantes do Campus, que possui 853 alunos. Entre os entrevistados $42,2 \%$ estão cursando entre o primeiro e o quinto período e $57,8 \%$ estão entre o sexto e o décimo segundo período, sendo que 45,9\% cursam Engenharia Agronômica, 43,7\% Engenharia de Alimentos, 7,4\% Bacharelado Interdisciplinar em Biossistemas e 3\% Engenharia Florestal ${ }^{7}$.

Analisando inicialmente as discussões da esfera macroestrutural, a primeira questão trouxe a seguinte situação: Você é

\footnotetext{
${ }^{7} \mathrm{O}$ baixo porcentual de alunos entrevistados em Engenharia Florestal e Bacharelado Interdisciplinar em Biossistemas se deve ao fato de o primeiro ser um curso recente com apenas três turmas, e com a média de 15 ingressantes por período. Já no segundo caso por ser um curso de bacharelado interdisciplinar, a maioria dos ingressantes migram para Engenharia Agronômica ou de Alimentos, o que justifica a discrepância entre esses grupos de estudantes.
} 
responsável por um processo seletivo dentro de uma empresa, na qual tem que escolher um entre dois engenheiros com perfis distintos. $\mathrm{O}$ primeiro é extremamente qualificado, porém um profissional que não é capaz de cometer nenhum ato antiético em favor do lucro da empresa. Entretanto o segundo é menos qualificado, porém seria capaz de romper com alguns valores éticos para aumentar o lucro da empresa. Quais dos dois funcionários você contrataria?

Essa questão mostrou que $86,7 \%$ dos estudantes afirmaram contratar uma pessoa mais qualificada e que age de acordo com os valores morais ditados pela sociedade, ainda que não implique na maximização do lucro. Apenas 13,3\% escolheriam uma pessoa menos qualificada e que rompe com alguns valores morais para aumentar os ganhos das empresas.

$\mathrm{Na}$ seguinte pergunta questionou-se: Você ocupa um cargo gerencial na prefeitura e para que um projeto que beneficiará a maioria da cidade seja aprovado, você precisa ofertar propina para alguns vereadores. Você faria isso em prol das camadas populares da cidade?

Analisadas as respostas, observou-se que os argumentos a favor da não corrupção diminuíram, porém ainda se mostraram superiores, pois $69,6 \%$ dos estudantes recusariam a oferta de propina, mesmo que isso a curto prazo atendesse as demandas emergências da cidade, enquanto que 30,4\% a ofertariam.

O terceiro dilema visou compreender de que forma os estudantes agiriam quando uma ação de denúncia para combater a corrupção poderia prejudicá-los diretamente no futuro ambiente profissional.

A pergunta envolvia o seguinte dilema: Você descobre que o gerente da empresa que trabalha está envolvido em um esquema de corrupção, você o denunciaria sabendo que poderia colocar em risco o seu emprego?

Através da análise dos dados foi possível observar um declínio em relação às respostas anteriores, porém mesmo correndo o risco de represarias $56,3 \%$ dos entrevistados denunciariam o chefe envolvido em um esquema de corrupção, enquanto $43 \%$ seriam coniventes com a corrupção do chefe, e 0,7\% optou por não responder à questão.

As análises apontam para uma forte moralidade advinda dos estudantes em um futuro profissional, uma vez que, teoricamente, a moralidade é definida como um valor ético onde se pratica o que é correto independentemente das recompensas que a imoralidade possa trazer. O discurso da moralidade, por tanto, não só vai de encontro ao dito de que os fins justificam não justificam os meios, como também condena quem o faz. 
Além das questões macroestruturais e com o intuito de compreender os juízos morais no cotidiano dos estudantes, o primeiro deles consistia na seguinte questão: Suponha que você vai fazer uma prova substitutiva da matéria mais importante do seu curso e a mesma acontecerá às 13 horas. Chegando ao Restaurante Universitário você se depara com uma fila gigantesca, porém um de seus amigos está bem à frente a ponto de ser servido, e tendo em vista que está atrasado, você pediria para passar na frente do seu colega?

As respostas dos estudantes apontaram que $72,6 \%$ furariam a fila, enquanto que $27,4 \%$ não o fariam, ainda que se prejudicassem no exame final.

Outro dilema relacionado à microesfera teve por intuito compreender como os estudantes agiriam em relação à delação quando um colega de classe está envolvido: Durante a aplicação da sua prova substitutiva o professor avisa que quem delatar algum aluno colando será contemplado com 10 pontos extras. Na prova você flagra um de seus colegas de turma colando. Assim você o delataria?

Os resultados apontam que apenas $7,4 \%$ dos estudantes delatariam um colega colando. Em contrapartida, a grande maioria representada por 92,6\% afirmaram não que fariam a delação. Ao comparar esta questão com a referente denúncia do gerente corrupto, constata-se uma significativa contradição de valores, observado nos gráficos abaixo.

Gráfico 1

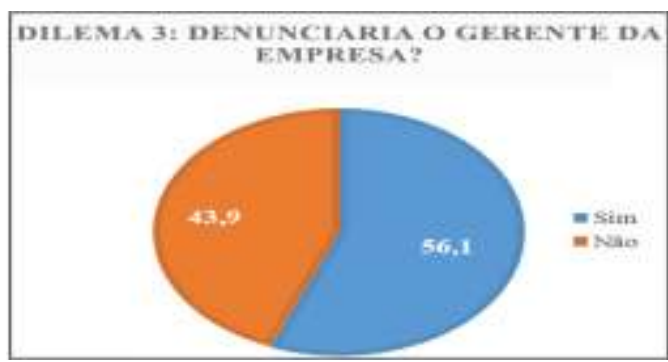

Gráfico 2

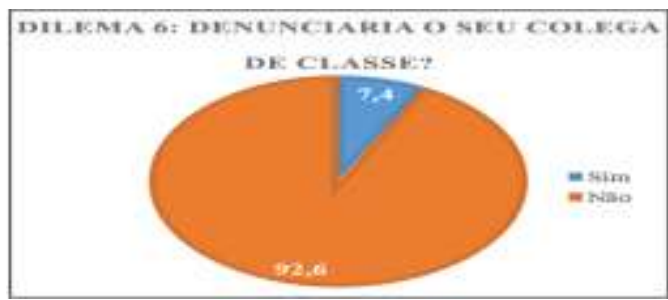

Fonte: Elaborado pelos autores, 2016.

Os dados comparados parecem indicar que se a presença de um discurso de moralidade de um futuro profissional é algo nítido na maioria dos estudantes, ao relativizar os dilemas ético no cotidiano, o moralismo toma evidência, baseado em um discurso que não condiz com a prática (VIANA, 2005), como a maioria respondeu que furaria a fila e tampouco denunciaria alguém que está burlando as regras.

Para além dos dilemas morais, buscouse compreender a percepção dos estudantes sobre a corrupção no Brasil e sobre como interpretam a sua própria conduta moral. Para tal, questionou-se: Você acha que a corrupção nas últimas décadas tem aumento, diminuído ou se mantido a mesma?

$\mathrm{O}$ resultado obtido mostra que a grande maioria dos estudantes, representada 
por $70,4 \%$ acredita que a corrupção no Brasil vem aumentando, enquanto que $27,4 \%$ se manteve a mesma e apenas $2,2 \%$ que tem diminuído nas últimas décadas.

Figueiredo (1996)no entanto, sustenta que a corrupção no Brasil foi uma herança herdada desde a vinda dos portugueses, e por tanto a mesma se perpetua desde os tempos da colonização, sem indícios de seu aumento. Porém, o discurso de que nunca se roubou tanto no Brasil, divulgado em grande parte pela grande mídia, parece ser reproduzida pelos estudantes, conforme registratambém os estudos de Silva e Santos (2009) e Marcos (et al., 2015).

Por fim, questionou-se: De um modo geral você considera o povo brasileiro corrupto?

Observou-se com as respostas que 92,\% dos entrevistados consideram a sociedade como um todo corrupta e apenas $6,7 \%$ não pensam assim. No entanto, ao indagar-se: Você se considera ético?,as respostas apontam que $80,7 \%$ dos estudantes se consideram éticos, enquanto apenas $17,8 \%$ não se consideram, $1,5 \%$ optou por não responder essa questão.

\section{Gráfico 3}

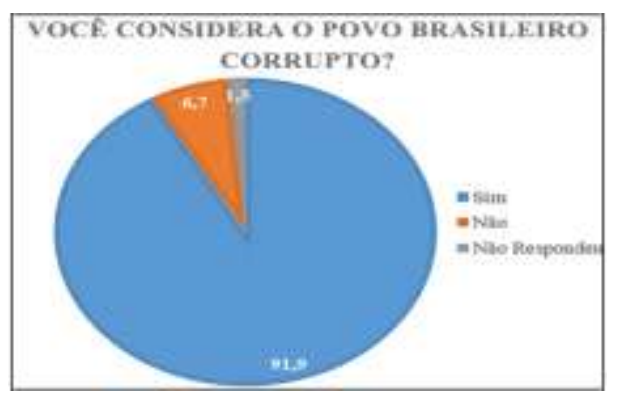

Gráfico 4

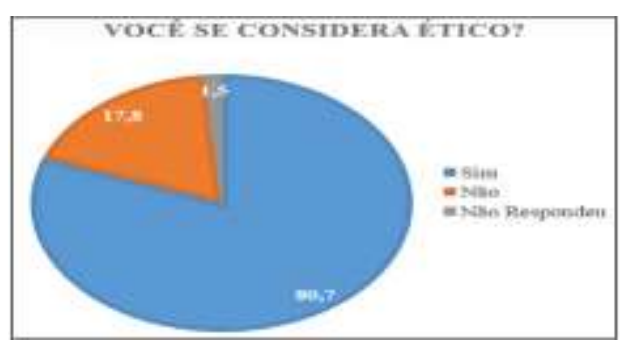

Fonte: Elaborado pelos autores, 2016.

Os dados mostram que ao se julgarem éticos e situarem o povo brasileiro como sendo corruptos, os estudantes se colocaram a parte da população nacional, mesmo que essa afirmação contraponha com as respostas dadas durante o questionário, o que parece corroborar mais uma vez o papel que exercem como juiz do moral, traço característico da onda moralista (VIANA, 2005).

Cabe assim, a própria naturalização dos mesmos que, o fato de considerarem atos do cotidiano como furar fila $(72,6 \%)$ e a não delação de colegas de classe $(92,6 \%)$ quando colam, como sendo atos normais e que por serem atos pequenos e comuns do seu cotidiano, são enquadrados como moralmente corretos.

\section{Considerações finais}

Com o presente artigo buscou-se compreender a percepção dos estudantes de uma universidade federal, que estiveram presentes nos movimentos sociais de protestos nas ruas em 2013 e 2015, sobre seus valores morais e consequente correlação com o 
moralismo e a moralidade presente na sociedade brasileira. Realizaram-se assim por meio de uma pesquisa quantitativa dilemas éticos e morais que envolviam tomadas de decisões que outrora colocavam em xeque os interesses individuais com o bem-estar da sociedade, bem como, julgavam a corrupção no Brasil e suas próprias condutas.

Os resultados da pesquisa apontaram para uma defesa de valores da moralidade nas supostas decisões acerca de um futuro profissional, porém contradições marcadas por decisões de cunho moralista referentes ao cotidiano dos estudantes. Registrou-se também uma crença no imaginário de que nunca se roubou tanto no Brasil e que a população brasileira é corrupta, porém uma visão a-crítica de suas próprias condutas.

Da mesma forma, durante o desenvolver do trabalho pôde-se concluir que existiu uma diferença tanto no perfil dos manifestantes que foram as ruas em 2013, 2015 e 2016, como também na maior parte dos temas abordados. Porém, principalmente a partir de 2015,constatou-se uma semelhança na forma como o moralismo se manteve presente nos discursos e no modo de agir dos manifestantes com os estudantes entrevistados.

Essa onda moralista presente não só no cotidiano dos estudantes, mas no Brasil como um todo, acaba por tornar relevante o fomento de estudos que visam dar maior profundidade as análises dos discursos moralistas, bem como, de uma retomada histórica dos traços culturais que ilustram a dupla moral que ainda norteia os contraditórios discursos da nação.

\section{Referências}

AVRITZER, L; FILGUEIRAS, F. Corrupção e controles democráticos no Brasil. (Textos para Discussão CEPALIPEA, 32). Brasília, DF: CEPAL. Escritório no Brasil/IPEA, 2011.

BORGES, P. C. A; et al.A linguagem das ruas. Análise qualitativa das demandas e protestos populares no Brasil de 2013. Atas CIAIQ, v.3, p. 331 - 337, 2014.

BOTELHO, M. L. O mundo como imagem e mobilização. Notas às "Primeiras Impressões" sobre as Manifestações. Revista Continentes (UFRRJ), ano 2, n.3, p. 121-132, 2013.

COSTA, R. C. Moralidade e Violência nas Escolas na Visão dos Professores. 2014. Tese (Mestrado em Psicologia) - Faculdade de Ciências e Letras de Assis - Universidade Estadual Paulista, São Paulo, Assis, 2014.

DURIGAN, G; RENÓ, D. Vídeo-Ativismo e conexões em rede nos protestos brasileiros de 2013.Razón y Palabra, n.90, jun/ago. 2015.

EGER, T. J. Dinheiro e moralidade no bolsa família: Uma perspectiva etnográfica. 2013. Tese (Mestrado em Antropologia Social) - Instituto de Filosofia e Ciências Humanas, Universidade Federal do Rio Grande do Sul, Porto Alegre, 2013.

FIGUEIREDO, L. R. A. Revoltas, fiscalidade e identidade colonial na América Portuguesa. Rio de Janeiro, Bahia e Minas Gerais, 16401761. 1996. 555 f. Tese (Doutorado em História) - Curso de Pós-Graduação em 
História, Universidade de São Paulo, São

Paulo, 1996.

LOYOLA, A. L. M. Vozes da crise: uma análise de discurso dos cartazes presentes nas manifestações de 2013 e 2015. 2015. 25

f. Monografia (Bacharelado em Comunicação Social) - Universidade de Brasília, Brasília, 2015.

MARCOS, A, et al.Subjetividade e mídia: um olhar sobre as manifestações de 2013.Revista Presença, v. 1, n. 1, p. 107-122, 2015.

MEDEIROS, J. Breve história das jornadas de junho: uma análise sobre os novos movimentos sociais e a nova classe trabalhadora no Brasil. História e Perspectivas, Uberlândia (51): 87-117,

PERES, D. F; et al. Democracia vs impeachment e as manifestaçõesdo povo brasileiro. XXIII Seminário de Iniciação Científica, UNIJUÍ,2015.

SCHWARTZMAN, S. Cadernos de nosso tempo. Editora Universidade de Brasília, 1981.

SILVA, E. F. G; SANTOS, S. E. B. O impacto e a influência da mídia sobre a produção da subjetividade. Associação Brasileira de Psicologia Social. Caruaru: Pernambuco, p.6, 2009.

SINGER, A. Classes e ideologias cruzadas. Revista Novos Estudos - CEBRAP 97, p. 2340, novembro de 2013.

VIANA, N. Crítica ao moralismo. 2015. Disponívelem: $<$ https://sites.google.com/site/a rtigosdenildoviana/moralismo >. Acesso em: 01 de mar. 2016.

VIEIRA PINTO, O. L. Os protestos no Brasil, ou sobre como a passagem de ônibus revelou contradições. $T$ he International Journal of Badiou Studies. v. 2, n.1, p. 156 - 159, 2013. 